\title{
KARAKTERISTIKE I PRETHODNA ANALIZA TROŠKOVA GOSPODARENJA ŠUMSKIM RESURSIMA*
}

\section{The characteristics and preliminary analyses of forest management costs}

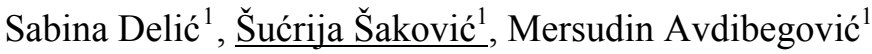

\begin{abstract}
From the aspect of the possibility to allocate the expenses to their exponents, total costs are divided to direct (individual and planning costs) and indirect (general, overhead costs). In the accounting of the costs according to the method of the Direct Costing or based on the method of marginal accounting, the qualification of expenses/costs differs. Based on this concept the expenses are divided to direct or the expenses of products and capacity, or expenses of technologic preparedness. The direct expenses include all direct costs and a part of general costs (variable part), while the costs of the capacity or the costs of technologic preparedness are exclusively general in their character.

This paper studied the character of the costs for conducting business in the forestry enterprises whose results showed extremely high expenses in the part of technological preparedness in the forest resources management. Forestry must take on these expenses regardless of the level of technological expenses, which result every year from the work in biological reproduction (forestation, breeding, conversion, road construction, etc). Presentation of their real assets is in the interest of the forest companies with the aim to objectively determine the prices in biological reproduction.
\end{abstract} Key words: direct costs, indirect costs, forest resources management, biological reproduction.

\section{Izvod}

Sa aspekta mogućnosti raspodjele troškova na njihove nosioce, ukupni troškovi se dijele na direktne (pojedinačne, troškove izrade) i indirektne (opće, režijske). Pri obračunu troškova po metodi Direct Costing ili po Metodi marginalnog računovodstva vrši se drugačija klasifikacija troškova. Po ovoj koncepciji troškovi se dijele na direktne ili troškove proizvoda i troškove kapaciteta ili troškove tehnološke pripremljenosti. Direktni

\footnotetext{
* Rad prezentiran na IV simpoziju poljoprivrede, veterinarstva, šumarstva i biotehnologije sa međunarodnim učešćem Strategija razvoja domaće proizvodnje, 21-23 septembar/rujan 2006. Zenica

${ }^{1}$ Šumarski fakultet Univerziteta u Sarajevu - Faculty of Forestry University of Sarajevo
} 
troškovi obuhvataju sve direktne troškove i dio općih troškova (varijabilni dio), dok su troškovi kapaciteta ili troškovi tehnološke pripremljenosti isključivo općeg karaktera.

U ovom radu je izvršeno istraživanje karaktera troškova poslovanja preduzeća šumarstva, čiji rezultati pokazuju izuzetno visoke troškove tehnološke pripremljenosti gospodarenja šumskim resursima. Šumarstvo mora snositi te troškove bez obzira na visinu tehnoloških troškova, koji su rezultat godišnjih radova iz područja biološke reprodukcije (pošumljavanja, njege, konverzije, izgradnje saobraćajnica i dr.). Prikazivanje njihovog realnog iznosa je u interesu preduzeća šumarstva, kako bi se što objektivnije utvrdila cijene biološke reprodukcije.

Ključne riječi: direktni troškovi, indirektni troškovi, gospodarenje šumskim resursima, biološka reprodukcija.

\section{UVOD - Introduction}

U ekonomskoj teoriji i praksi, sa stanovišta mogućnosti raspodjele troškova elemenata proizvodnje na njihove nosioce, ukupni troškovi se mogu podijeliti na direktne, pojedinačne ili troškove izrade i na indirektne, opće ili režijske.

Direktni troškovi su takvi troškovi koji se mogu direktno, neposredno rasporediti na pojedine nosioce troškova. Opći troškovi su zajednički i oni se ne mogu direktno, bez upotrebe nekog ključa, obuhvatiti po nosiocima, tj. učincima. Njih čine svi troškovi administrativno-upravne funkcije preduzeća, odnosno troškovi upravnoprodajne režije, te opći troškovi proizvodnje.

Pored ove klasifikacije troškova, u preduzećima gdje se kalkulacija troškova obavlja po metodi Direct Costing ili po Metodi marginalnog računovodstva, vrši se drugačija klasifikacija po kojoj se svi troškovi dijele na direktne troškove (troškovi proizvoda) i troškove kapaciteta (troškovi tehnološke pripremljenosti).

U prvu grupu troškova spadaju ne samo direktni troškovi po klasičnoj klasifikaciji, nego i svi troškovi koji nastaju u procesu proizvodnje i poslovanja preduzeća uopće. Visina ovih troškova zavisi od toga da li preduzeće radi ili ne. U slučaju prekida proizvodnje, ovi troškovi ne bi ni postojali. Dakle, ovi troškovi su reagibilni na promjenu obima proizvodnje, te su po svom karakteru varijabilni.

S druge strane, troškovi kapaciteta ili troškovi tehnološke pripremljenosti su uvijek isti. Ovi troškovi nisu, ustvari, ni izazavani samom proizvodnjom nego su rezultat njene pripreme, uspostavljanja kapaciteta $\mathrm{i}$ organizacione strukture njegovog korištenja.

To znači da po principima ove klasifikacije direktni troškovi obuhvataju sve pojedinačne troškove i dio općih troškova (varijabilni dio), dok su troškovi kapaciteta ili tehnološke pripremljenosti isključivo općeg karaktera i uslovno se mogu poistovjetiti sa fiksnim troškovima.

Ova podjela je prisutna naročito kod onih djelatnosti sa izrazito visokim organskim sastavom elemenata proizvodnje, $u$ kojima se mora respektovati neotklonjivost indirektnih troškova. 


\section{CILJ I METOD RADA - The aim and the methods of work}

U ovom radu je izvršena analiza strukture troškova gospodarenja šumskim resursima sa ciljem ocjene njihovog karaktera. Ova analiza ima značaj sa aspekta objektivnog utvrđivanja cijena u šumarstvu, a naročito cijene biološke reprodukcije. Zato je izvršeno „uslovno“ razgraničenje troškova djelatnosti uzgajanja šuma i iskorištavanja šuma na bazi stope općih troškova, tj. metodom kalkulacije pomoću dodatka, kako bi se locirali opći troškovi sa ciljem njihove racionalizacije.

\section{REZULTATI ISTRAŽIVANJA - The results of the study}

Troškovi tehnološke pripremljenosti u djelatnosti šumarstva su izuzetno visoki i šumarstvo ih mora snositi bez obzira na visinu tehnoloških troškova, koji se odnose na godišnje radove iz područja biološke reprodukcije kao što su: pošumljavanje, njega, konverzija, izgradnja saobraćajnica i dr. Međutim, kod nas je u praksi šumarskih preduzeća evidentno izostavljanje ovih troškova pri utvrđivanju cijene koštanja radova biološke reprodukcije, čime se vještački snižava cijena biološke reprodukcije.

Istraživanja su provedena u preduzeću šumarstva „Unsko-sanske šume“, gdje je izvršena analiza troškova pri konkretnoj realizaciji radova biološke reprodukcije, te ocjena njihovog karaktera. Struktura ostvarenih troškova gospodarenja šumskim resursima u 2002. godini je prikazana u Tabeli 1. i na Graf. 1.

Tabela 1. Struktura troškova u 2002. godini

Table 1. Structure of the costs, 2002

\begin{tabular}{|l|r|c|}
\hline \hline Vrsta troškova & $\begin{array}{c}\text { Iznos } \\
(000 \mathrm{KM})\end{array}$ & \% učešće \\
\hline \hline Troškovi radne snage & $7.913,9$ & 26,4 \\
\hline Materijalni troškovi i usluge & $6.890,0$ & 23,0 \\
\hline Troškovi amortizacije & $1.488,4$ & 5,0 \\
\hline Troškovi biološke reprodukcije & $4.195,3$ & 14,0 \\
\hline Troškovi sječe, izrade i izvoza & $8.950,0$ & 29,9 \\
\hline Ostali troškovi & 509,1 & 1,7 \\
\hline \hline Ukupni troškovi & $29.946,7$ & 100,0 \\
\hline
\end{tabular}

Najveću stavku u ukupnim troškovima čine troškovi sječe, izrade i izvoza koji iznose $29,9 \%$ od ukupno ostvarenih troškova, a zatim slijede: troškovi radne snage $26,4 \%$, materijalni troškovi i usluge $23,0 \%$, troškovi biološke reprodukcije $14,0 \%$, amortizacija osnovnih sredstava $5,0 \%$, te ostali troškovi $1,7 \%$. 


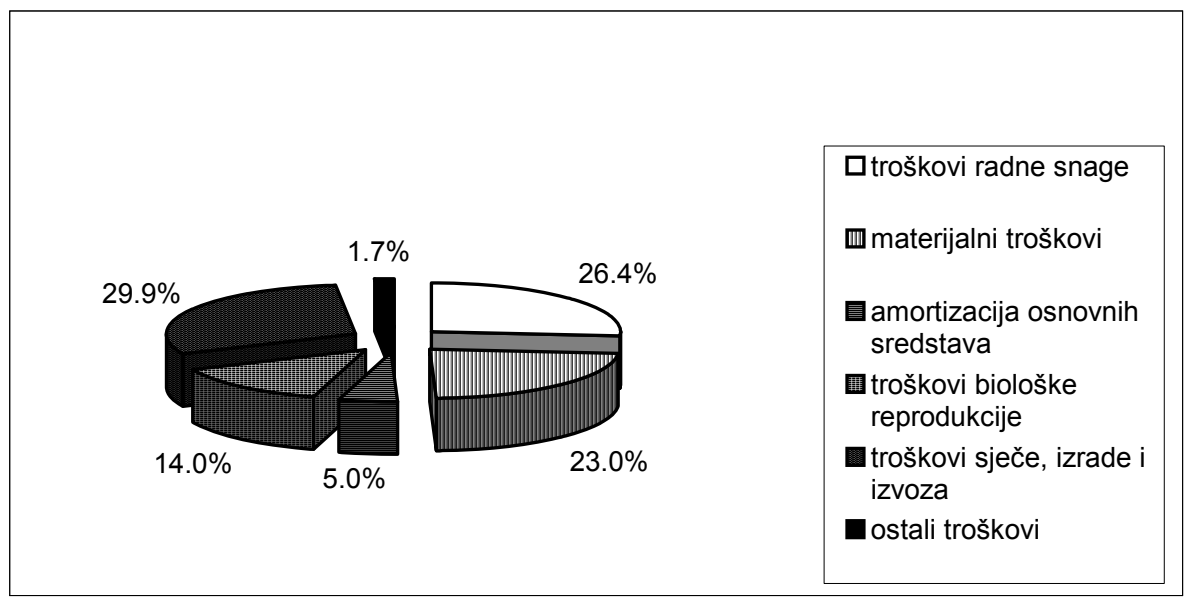

Graf 1. Struktura troškova poslovanja preduzeće „Unsko-sanske šume“ u 2002. godini

Graph 1. Management costs structure of forest enterprise „Unsko-sanske šume“ in 2002

$\mathrm{Na}$ osnovu izvršene analize strukture ostvarenih troškova koji se odnose na cjelokupno gospodarenje šumskim resursima i ocjene njihovog karaktera, može se zaključiti da je učešće direktnih troškova oko 61\%, dok indirektni (opći) troškovi učestvuju sa oko 39 \%. Najveći dio indirektnih troškova je fiksnog karaktera i može se smatrati da oni predstavljaju troškove kapaciteta, odnosno troškove tehnološke pripremljenosti koje preduzeće mora snositi, bez obzira na tehnološke troškove koji su posljedica izvršenog obima proizvodnje.

U cilju utvrđivanja realnih troškova koji se odnose na djelatnost uzgajanja šuma i na djelatnost iskorištavanja šuma, izvršeno je "uslovno" razgraničenje ukupnih troškova poslovanja preduzeća na ove djelatnosti. Za takvo razgraničenje je primjenjena kalkulacija pomoću dodatka, gdje su korištene parcijalno izračunate stope općih troškova sa ciljem preciznije raspodjele općih troškova radne snage, općih materijalnih troškova te općih troškova osnovnih sredstava. Prosječna stopa općih troškova na nivou preduzeća je 63,2\%. Na osnovu nje se može izvršiti gruba raspodjela općih troškova.

Razgraničeni troškovi kao i njihovo relativno učešće u ukupnim troškovima pojedinih djelatnosti prikazani su u Tabeli 2 .

Prema dobivenim pokazateljima, na djelatnost uzgajanja šuma otpada 47,8 \% od ukupnih troškova preduzeća, dok se preostalih $52,2 \%$ troškova može pripisati djelatnosti iskorištavanja šuma. Analizirajući osobine i karakter troškova pojedinih djelatnosti došlo se do interesantnih pokazatelja. 
Tabela 2. Razgraničeni troškovi poslovanja na djelatnosti uzgajanja šuma i iskorištavanja šuma

Table 2. Allocated management costs in the silviculture and forest utilization activity

\begin{tabular}{|c|c|c|c|c|c|c|c|}
\hline \multirow{3}{*}{ Vrsta troškova } & \multicolumn{3}{|c|}{ Uzgajanje šuma } & \multicolumn{3}{|c|}{ Iskorištavanje šuma } & \multirow{2}{*}{$\begin{array}{l}\text { Ukupni } \\
\text { troškovi } \\
\text { gospodarenja }\end{array}$} \\
\hline & $\begin{array}{l}\text { Direktni } \\
\text { troškovi }\end{array}$ & $\begin{array}{c}\text { Opći } \\
\text { troškovi }\end{array}$ & Ukupno & $\begin{array}{l}\text { Direktni } \\
\text { troškovi }\end{array}$ & $\begin{array}{l}\text { Opći } \\
\text { troškovi }\end{array}$ & Ukupno & \\
\hline & \multicolumn{7}{|c|}{$000 \mathrm{KM}$} \\
\hline $\begin{array}{l}\text { Troškovi radne } \\
\text { snage }\end{array}$ & $2.549,7$ & $3.319,1$ & $5.868,8$ & 888,5 & $1.156,6$ & $2.045,1$ & $7.913,9$ \\
\hline $\begin{array}{l}\text { Materijalni troškovi } \\
\text { i usluge }\end{array}$ & $1.315,2$ & $1.976,8$ & $3.292,0$ & $1.437,2$ & $2.160,7$ & $3.597,9$ & $6.889,9$ \\
\hline $\begin{array}{l}\text { Troškovi } \\
\text { amortizacije }\end{array}$ & 109,7 & 579,3 & 689,0 & 127,3 & 672,1 & 799,4 & $1.488,4$ \\
\hline $\begin{array}{l}\text { Troškovi biološke } \\
\text { reprodukcije }\end{array}$ & $4.195,3$ & & $4.195,3$ & & & & $4.195,3$ \\
\hline $\begin{array}{l}\text { Troškovi sječe, } \\
\text { izrade i izvoza }\end{array}$ & & & & $8.950,0$ & & $8.950,0$ & $8.950,0$ \\
\hline Ostali troškovi & 100,3 & 154,3 & 254,6 & 101,4 & 153,2 & 254,6 & 509,2 \\
\hline Ukupni troškovi & $8.270,2$ & $6.029,5$ & $14.299,7$ & $11.504,4$ & $4.142,6$ & $15.647,0$ & $29.946,7$ \\
\hline \multirow{2}{*}{$\begin{array}{c}\text { Relativno učešće } \\
\text { pojedinih troškova } \\
(\mathbf{0})\end{array}$} & 57,8 & 42,2 & $10 \mathbf{1 0 0 , 0}$ & $73, \mathbf{7 3 , 5}$ & 26,5 & $10 \mathbf{1 0 0 , 0}$ & \\
\hline & \multicolumn{3}{|c|}{$(47,8)$} & \multicolumn{3}{|c|}{$(52,2)$} & $(100,0)$ \\
\hline
\end{tabular}

U djelatnosti uzgajanja šuma zastupljenost direktnih troškova u ukupnim troškovima je 57,8 \%, dok 42,2 \% troškova ima karakter općih troškova. Opći troškovi gotovo u cjelokupnom iznosu spadaju u troškove tehnološke pripremljenosti, tj. troškove postojanja preduzeća. Oni postoje i onda kada se ne obavljaju tehnološke aktivnosti. Zbog njihovog značajnog udjela u ukupnim troškovima, ukupni troškovi biološke reprodukcije se moraju opteretiti i sa ovim dijelom troškova, kako bi se što objektivnije utvrdila cijena svih radova biološke reprodukcije.

Odnos troškova u djelatnosti iskorištavanja šuma je drugačiji. Oko 73,5\% je direktnih, a ostatak od 26,5 \% ima karakter općih troškova. Ovako visoko učešće direktnih troškova $u$ djelatnosti iskorištavanja šuma objašnjava se relativno visokim učešćem troškova sječe, izrade i izvoza, koji iznose 57,2 \% od ukupnih troškova djelatnosti iskorištavanja, a imaju karakter direktnih troškova. Ilustracije radi, struktura troškova ove dvije djelatnosti je prikazana grafički (Graf.2. i Graf.3.). 


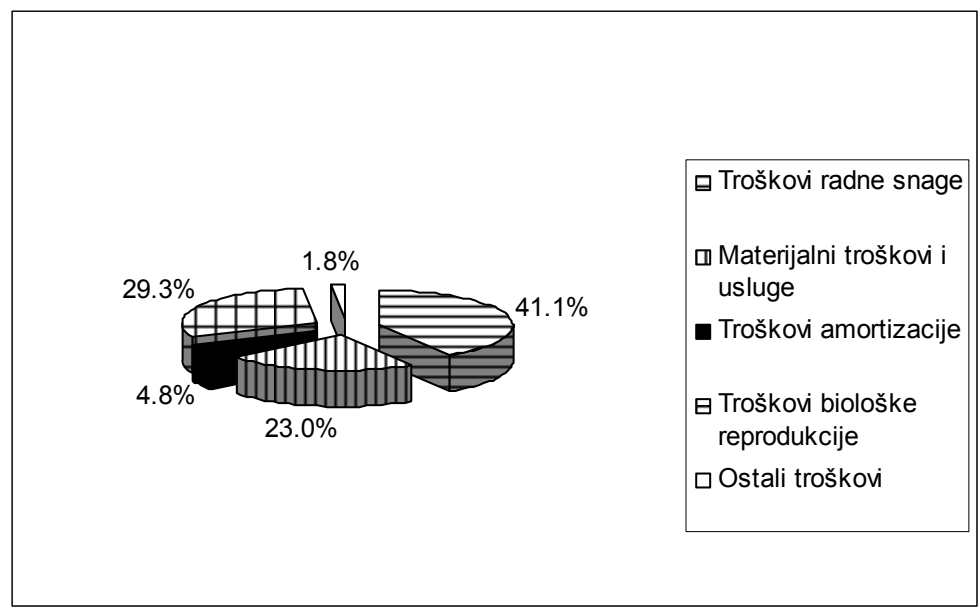

Graf 2. Struktura troškova djelatnosti uzgajanja šuma

Graph 2. Costs structure of silviculture activity

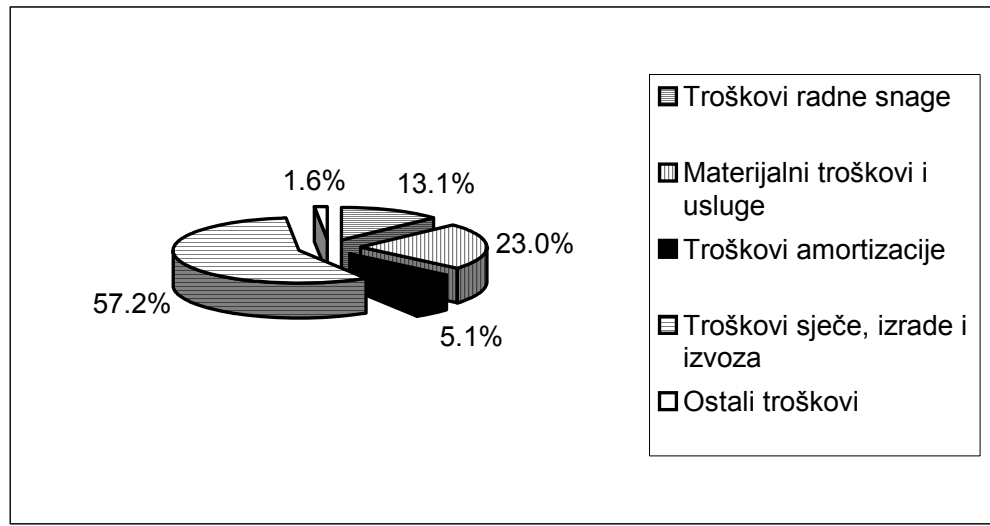

Graf 3. Struktura troškova djelatnosti iskorištavanja šuma Graph 3. Costs structure of forest utilization activity

\section{ZAKLJUČNA RAZMATRANJA - Conclusions and discussion}

Analiza strukture i karakteristika troškova koji nastaju u gospodarenju šumskim resursima je pokazala da je učešće direktnih troškova u ukupnim troškovima $61 \%$, dok opći (indirektni) troškovi učestvuju sa $39 \%$. To ukazuje na veoma visoku zastupljenost troškova koji nisu u direktnoj vezi sa obimom izvršenih tehnoloških aktivnosti u djelatnosti šumarstva. Oni po svom karakteru pripadaju fiksnim troškovima koje preduzeće mora snositi u punom iznosu, bez obzira na tehnološke troškove proizvodnje. 
Nakon izvršenog "uslovnog “ razgraničenja troškova uzgajanja i iskorištavanja šuma, došlo se do podatka da veći dio općih troškova pripada djelatnosti uzgajanja šuma. U ukupnim troškovima djelatnosti uzgajanja šuma na direktne troškove otpada $57,83 \%$, a na opće $42,17 \%$.

Omjer troškova u iskorištavanju šuma je drugačiji. Na direktne troškove otpada $73,52 \%$, a opći troškovi iznose 26,48 \% od ukupnih troškova. Razlog za ovakav odnos se nalazi u činjenici da najveći udio troškova u iskorištavanju šuma čine troškovi sječe, izrade i izvoza i to 57,2 \%, a oni imaju karakter direktnih troškova.

Saznanje o visokom učešću općih troškova, koje je naročito izraženo u djelatnosti uzgajanja šuma, veliku važnost ima pri utvrđivanju realne cijene koštanja biološke reprodukcije, jer se pored direktnih troškova, radovi iz područja biološke reprodukcije moraju opteretiti sa pripadajućim dijelom općih troškova, u skladu sa stopom općih troškova. Stopa općih troškova na nivou ispitivanog preduzeća je 63,2 $\%$, dok posmatrano po „uslovno" razgraničenim djelatnostima, u djelatnosti uzgajanja šuma iznosi 72,91\%, a u iskorištavanju šuma $36,01 \%$.

Prikazivanje realnog iznosa općih troškova u interesu je preduzeća šumarstva kako bi se što objektivnije utvrdila cijena biološke reprodukcije. Dakle, zbog evidentno visokog učešća ovih troškova u ukupnim troškovima gospodarenja, nužno im je posvetiti odgovarajuću pažnju sa ciljem njihove racionalizacije.

\section{LITERATURA - Literature}

1. BLAŠKO, E. (1968): Kalkulacije u industrijskim poduzećima, Informator, Organizacija i ekonomika poduzeća, (1968), Zagreb

2. DeLIĆ, S. (2006): Istraživanje modela finansiranja biološke reprodukcije u šumarstvu Bosne i Hercegovine, doktorska disertacija, Šumarski fakultet, Sarajevo

3. KRALJIĆ, B. (1984): Razgraničenje i kalkulacija jednostavne biološke godišnje reprodukcije drva - sumarno i po jedinicama tečajnog drvnog prirasta, odnosno godišnje sječne drvne mase, Radovi, Šumarski institut, Jastrebarsko, Broj 63, godina XIX, str. 1-29, Zagreb

4. ŠAKOVIĆ, Š. Neke ekonomske karakteristike proizvodnje u šumarstvu kao osnovice za formulaciju šumarske politike

5. ŠunJić-Beus, M., Berberović, Š., STAVRIĆ, B. (1999): Ekonomika preduzeća, Ekonomski fakultet, Sarajevo

6. Unsko -sanske šume (2002): Plan rada i poslovanja za 2002. godinu, Bosanska Krupa

7. Unsko-sanske šume (2003): Izvještaj o poslovanju preduzeća za period januardecembar 2002. godine, Bosanska Krupa

8. Zakon o šumama (2002): Službene novine Federacije BiH 


\section{SUMMARY - Sažetak}

The results of the analysis of the structure and characteristics of costs in forest resources management show that participation of general expenses is $39 \%$, and the direct (variable) expenses comprise $61 \%$ out of the overall expenses in the forest resources management. This points at an exceptionally high share of expenses which are not directly related with the ratio of performance of technological activities in the forestry business. Based on their character they fall under the fixed expenses that a company has to cover in full, regardless of the technological expenses in production. After completed "conditional" division of expenses in the silviculture and exploitation of forests, we came to conclusion that greater part of general expenses belongs to the silviculture activity. Within the overall costs of forest breeding 57,83\% falls to the direct expenses and $42,17 \%$ to general. The knowledge of high costs in general expenditure, which is particularly expressed in the forest breeding activity, has great significance in determining realistic prices for the costs of biological reproduction. Appart from direct costs, the activities from the area of biological reproduction must therefore be burdened with pertaining part of general expenses. 